\title{
Restoration of fertility by gonadotropin replacement in a man with hypogonadotropic azoospermia and testicular adrenal rest tumors due to untreated simple virilizing congenital adrenal hyperplasia
}

\author{
Julia Rohayem1, Frank Tüttelmann², Con Mallidis ${ }^{3}$, Eberhard Nieschlag ${ }^{1,4}$, \\ Sabine Kliesch ${ }^{1}$ and Michael Zitzmann ${ }^{1}$ \\ ${ }^{1}$ Center of Reproductive Medicine and Andrology, Clinical Andrology, University of Muenster, Albert-Schweitzer- \\ Campus 1, Building D11, D-48149 Muenster, Germany, ${ }^{2}$ Institute of Human Genetics and ${ }^{3}$ Institute of Reproductive \\ and Regenerative Biology, Center of Reproductive Medicine and Andrology, University of Muenster, Muenster, \\ Germany and ${ }^{4}$ Center of Excellence in Genomic Medicine Research, King Abdulaziz University, Jeddah, Saudi Arabia
}

\author{
Correspondence \\ should be addressed \\ to J Rohayem \\ Email \\ Julia.Rohayem@ \\ ukmuenster.de
}

\begin{abstract}
Context: Classical congenital adrenal hyperplasia (CAH), a genetic disorder characterized by 21-hydroxylase deficiency, impairs male fertility, if insufficiently treated.

Patient: A 30-year-old male was referred to our clinic for endocrine and fertility assessment after undergoing unilateral orchiectomy for a suspected testicular tumor. Histopathological evaluation of the removed testis revealed atrophy and testicular adrenal rest tumors (TARTs) and raised the suspicion of underlying $\mathrm{CAH}$. The remaining testis was also atrophic $(5 \mathrm{ml})$ with minor TARTs. Serum 17-hydroxyprogesterone levels were elevated, cortisol levels were at the lower limit of normal range, and gonadotropins at prepubertal levels, but serum testosterone levels were within the normal adult range. Semen analysis revealed azoospermia. CAH was confirmed by a homozygous mutation g.655A/C $>$ G (IVS2-13A/C $>$ G) in CYP21A2. Hydrocortisone $\left(24 \mathrm{mg} / \mathrm{m}^{2}\right)$ administered to suppress ACTH and adrenal androgen overproduction unmasked deficient testicular testosterone production. As azoospermia persisted due to sustained hypogonadotropic hypogonadism, a combined s.c. gonadotropin replacement with human chorionic gonadotropin (hCG) (1500 IU twice weekly) and FSH (human menopausal gondadotropin (hMG) $150 \mathrm{IU}$ three times weekly) was initiated.

Results: Normalization of testosterone levels and a stable low sperm concentration ( $0.5 \mathrm{mill} / \mathrm{ml})$ with good sperm motility ( $85 \%$ A + B progressive) were achieved within 21 months of treatment. Despite persisting TARTs, while receiving treatment, the patient successfully impregnated his wife twice, the latter impregnation leading to the birth of a healthy girl. Conclusions: TARTs in unrecognized (simple virilizing) CAH may lead to unnecessary orchiectomy. In hypogonadotropic, azoospermic $\mathrm{CAH}$, a combined treatment with oral corticosteroids and subcutaneously administered hCG and FSH can successfully restore testicular testosterone production and fertility, even if only one hypoplastic and atrophic testis with adrenal rest tumors is present.
\end{abstract}




\section{Introduction}

Classical congenital adrenal hyperplasia (CAH) is an autosomal recessive disorder characterized by adrenal 21-hydroxylase deficiency due to homozygous mutations in the CYP21A2 gene (MIM 613815). The resulting enzymatic failure causes impairment of adrenal glucocorticoid and mineralocorticoid production. In contrast to the salt-wasting (SW) form, mineralocorticoid production is (partially) preserved in simple virilizing (SV) CAH. Overproduction of adrenal steroids, i.e. 17-hydroxyprogesterone (17-OHP), androstenedione, DHEAS, and testosterone, occurs in both forms, as a consequence of pituitary adrenocorticotropin (ACTH) hypersecretion. Treatment of CAH aims at suppressing ACTH secretion. If this suppression is insufficient, an ACTH-driven proliferation of testicular adrenal rest tumors (TARTs) $(1,2,3,4)$ and progressive spermatogenic tubular atrophy may ensue. These mechanisms, alongside gonadotropin suppression by adrenal androgens, can impair fertility. Herein, we report on a patient with SV CAH who remained undiagnosed and untreated for 30 years before presenting with hypogonadotropic azoospermia and TARTs.

This case report gives insight into the pathophysiology and consequences of $\mathrm{CAH}$ on the reproductive tract when it is left untreated for an extended period. Based on this individual case, we weigh and discuss treatment options and propose a new therapeutic approach for the restoration of fertility.

\section{Case report}

A 30-year-old Caucasian male was referred to our clinic for endocrine and reproductive evaluation after undergoing left-sided orchiectomy, as histological evaluation of the tumor raised the suspicion of possible CAH.

\section{Methods}

Informed consent was provided by the patient for all procedures conducted. Serum testosterone and 17-OHP levels were measured using commercial ELISA kits (DRG Instruments GmbH, Marburg, Germany and IBL International, Hamburg, Germany, respectively). Sex hormone-binding globulin (SHBG) levels and serum luteinizing hormone (LH) and follicle-stimulating hormone (FSH) levels were determined using highly specific time-resolved fluoroimmunoassays (Autodelfia, Freiburg, Germany). Free testosterone levels were calculated from SHBG and total serum testosterone levels, assuming fixed albumin levels, according to the generally accepted procedure as described previously (5). The assessment of semen samples was done according to WHO guidelines (6).

Recent medical history Unilateral orchiectomy was performed on the suspicion of a testicular tumor based on ultrasound imaging. The scans revealed two distinct regions of low echogenicity ( 8 and $13 \mathrm{~mm}$ ) in the left testis and two smaller regions of low echogenicity in the right testis. In addition, bilateral testicular atrophy (i.e. testicular volumes of $5 \mathrm{ml}$ ) was diagnosed with sperm being absent in the ejaculate, while tests for testicular tumor markers ( $\beta$-human chorionic gonadotropin (hCG) and AFP) were negative. Examination of fresh frozen sections led to the diagnosis of a 'Leydig cell tumor'. More expansive histopathological evaluation confirmed 'nodular hyperplasia of cells resembling Leydig cells' and tubular atrophy with arrest of spermatogenesis at the spermatocyte stage. The absence of mitotic figures and of Reinke's crystals gave rise to a diagnosis of a TART with a suspicion of underlying CAH.

At the time of examination, the patient was not taking any medication.

Past medical history - During childhood, the patient had been treated with corticosteroids for penile enlargement for a few months. The reason for discontinuing this treatment remained unexplained. He had stopped growing at the age of 11 years. There was no history of other previous illnesses.

Physical examination - Initial assessment revealed short stature $(156 \mathrm{~cm}<5$ th percentile), obesity (76 kg; BMI: $31 \mathrm{~kg} / \mathrm{m}^{2}$ ), skin hyperpigmentation, and a single atrophic right testis.

The results of the first endocrine assessments are given in Table 1 (column 1). Specifically, 17-OHP levels were extremely elevated, cortisol levels were at the lower limit of the normal range, and gonadotropins were at low/prepubertal levels, but serum testosterone levels were within the normal range for an adult male. Semen analysis revealed azoospermia.

Molecular genetic testing $>$ Sequencing of the 21-hydroxylase gene (CYP21A2) revealed a homozygous mutation g.655A/C $>$ G (IVS2-13A/C $>$ G, often referred to as I2G). Quantitative PCR confirmed the presence of two 
Table 1 Hormone values at the diagnosis of $\mathrm{CAH}$ and during 5 years of treatment.

\begin{tabular}{l}
\hline \\
\\
\hline $17-O H P(0.1-4.9 \mathrm{nmol} / \mathrm{l})$ \\
Cortisol $(50-250 \mathrm{nmol} / \mathrm{l})$ \\
Androstenedione \\
$(0.7-3.6 \mathrm{ng} / \mathrm{ml})$ \\
DHEAS $(770-5280 \mathrm{ng} / \mathrm{ml})$ \\
Testosterone $(>12 \mathrm{nmol} / \mathrm{l})$ \\
Free testosterone \\
$(>250 \mathrm{pmol} / \mathrm{l})$ \\
LH 0 min $(2-10 \mathrm{U} / \mathrm{l})$ \\
FSH min $(1-7 \mathrm{U} / \mathrm{l})$ \\
Testicular volume (single) \\
$(12-35 \mathrm{ml})$ \\
\hline
\end{tabular}

\begin{tabular}{c}
\hline $\mathbf{1}$ \\
\hline At CAH \\
diagnosis at the \\
age of 30 years \\
\hline 73684 \\
67.5 \\
41
\end{tabular}

$\frac{\mathbf{2}}{\text { After }} \frac{\mathbf{3}}{\text { After }}$

\begin{tabular}{|c|}
\hline 4 \\
\hline $\begin{array}{c}\text { During } \mathrm{HC}+\mathrm{TU} \\
\text { treatment for } \\
2 \text { years }\end{array}$ \\
\hline $27-188^{*}$ \\
\hline $\begin{array}{c}77-216 \\
10\end{array}$ \\
\hline
\end{tabular}

\begin{tabular}{c}
$\frac{\mathbf{5}}{\text { During } \mathrm{HC}+\mathrm{hCG}}$ \\
$\begin{array}{c}\text { treatment for } \\
1 \text { year }\end{array}$ \\
\hline $35-158$
\end{tabular}

\begin{tabular}{c}
$\frac{\mathbf{6}}{\text { After } 3 \text { months }}$ \\
of HC+hCG+ \\
FSH treatment \\
\hline 188
\end{tabular}

\begin{tabular}{c}
$\frac{\mathbf{7}}{\text { After } 21 \text { months }}$ \\
of HC+hCG+ \\
FSH treatment \\
\hline 153 \\
185
\end{tabular}

$\begin{array}{rrc}27.2 & 16.5 & 6.4 \\ 881.2 & 463.9 & 183\end{array}$

$2510-2770$
$14-19$

10.0
289

$\begin{array}{cc}14.3 & 22 \\ & 662 \\ \ll 0.1 & \ll 0.1 \\ 4.7 & 2.6 \\ 5 & 7\end{array}$

\begin{tabular}{lll}
0.1 & 0.2 & 0.4 \\
0.3 & 0.3 & 1.3 \\
5 & & \\
\hline
\end{tabular}

$<0.1$
$\ll 0.1$
$\quad 5$

$\ll 0.1$ $\ll 0.1$

ND, not determined; HC, hydrocortisone; TU, testosterone undecanoate; 17-OHP, 17-hydroxyprogesterone; hCG, human chorionic gonadotropin. *, varying

functional CYP21A2 alleles, a finding also supported by the heterozygous polymorphism g.2691A $>$ G. CYP21A2 sequencing of the patient's wife revealed no pathogenic mutations. During genetic counseling, the patient and his wife were informed that there was no increased risk of a child with CAH.

Diagnosis, therapy, and results $>$ A combination of the patient's history, endocrine assessment, and molecular genetic testing established the diagnosis of SV CAH.

Hydrocortisone treatment $\left(12 \mathrm{mg} / \mathrm{m}^{2}\right.$ p.o. per day, divided into three doses, with the morning dose being highest) was initiated, which markedly reduced adrenal androgen overproduction. A normal level of 17-OHP could not be achieved, despite increasing the dose to $24 \mathrm{mg} / \mathrm{m}^{2}$ daily. Despite hydrocortisone treatment, gonadotropin levels continued to exhibit a sustained suppression. A drop in serum testosterone levels below the normal adult range unmasked the adrenal origin of the previously normal serum testosterone levels (Table 1 , columns 2 and 3). As the patient exhibited symptoms of androgen deficiency, i.e. a decrease in libido and a depressive mood, testosterone undecanoate $1000 \mathrm{mg}$ was injected intramuscularly every 3 months. Consequently, gonadotropin levels remained suppressed (Table 1, column 4). After 2 years of testosterone replacement, the patient expressed his wish for a child. To overcome the azoospermia, testosterone substitution was stopped and, in the absence of adequate serum LH levels, the endogenous testicular testosterone production by the Leydig cells was stimulated by s.c. injections of hCG $1500 \mathrm{IU}$ twice weekly. This successfully restored testosterone (of testicular origin) to near-normal levels (Table 1, column 6). However, hCG treatment hampered any re-establishment of a normal endogenous gonadotropin secretion by the pituitary (Table 1, column 5). After a year of hCG treatment, FSH (hMG) $150 \mathrm{IU}$, injected subcutaneously three times weekly, was added to the regimen, and resulted in the initiation of spermatogenesis after 3 months.

Assessment of semen samples, provided after 3-7 days of abstinence, revealed a continuous improvement of

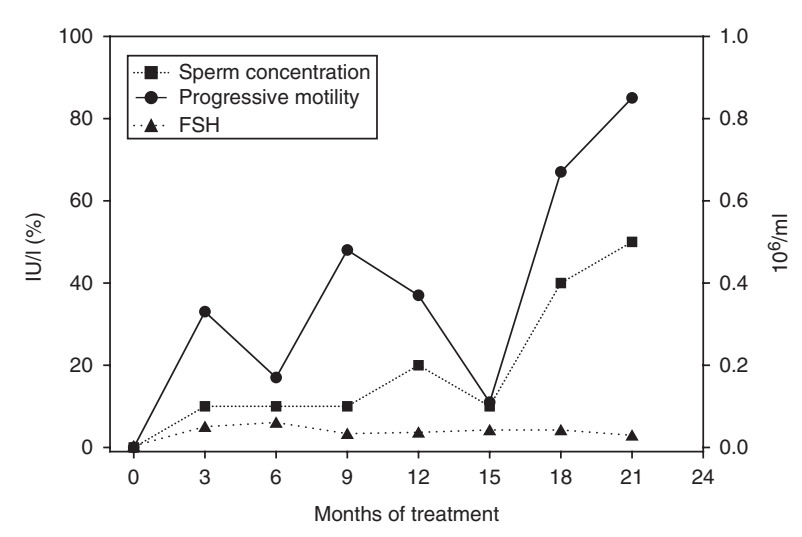

\section{Figure 1}

Increase in sperm concentration ( $\mathrm{mill} / \mathrm{ml}$ ) and progressive sperm motility ( $A+B$ progressive) during 21 months of gonadotropin (hCG and FSH) replacement therapy. Peak sperm count achieved at 21 months was stable during the following 2 years of continued therapy. 

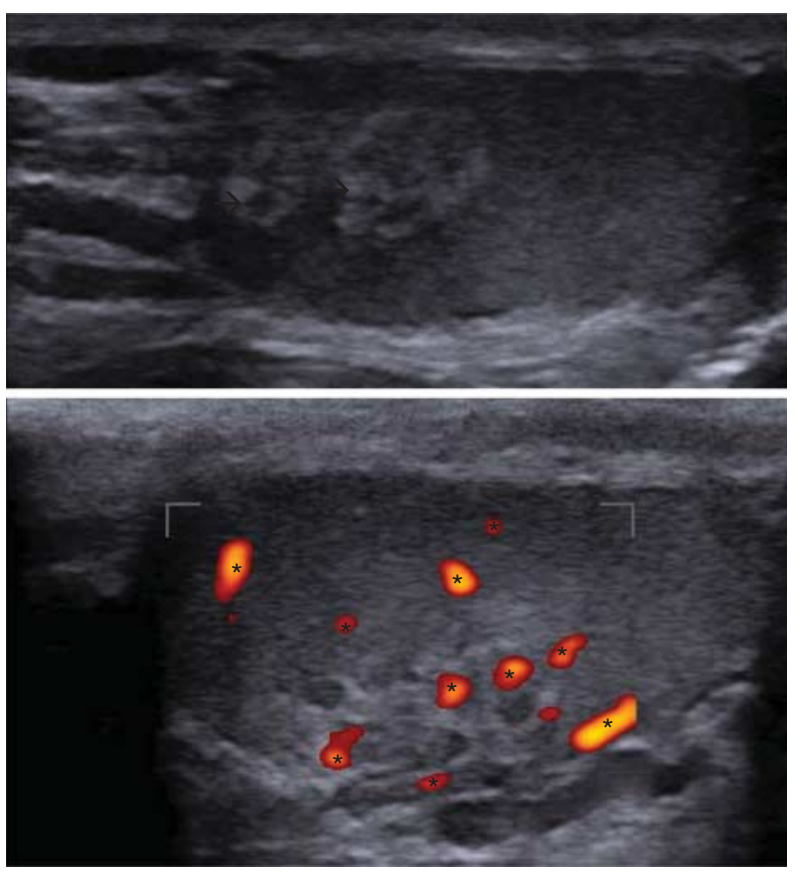

\section{Figure 2}

Longitudinal ultrasound image (B-mode) of the remaining right testis (upper panel): TARTs, presenting as hypoechogenic regions with hyperechogenic margins in the rete testis $(\rightarrow)$. Color Doppler (lower panel): homogenous perfusion of the testis (*), no hyperperfusion in the TARTs. Full colour version of this figure available via http://dx.doi.org/10.1530/EJE-13-0449.

sperm quality (Fig. 1), culminating in a stable but low sperm concentration $(0.5 \mathrm{mill} / \mathrm{ml})$ with excellent motility (85\% A + B progressive) and normal morphology (11\% normal forms) after 21 months of the combined s.c. gonadotropin (hCG/FSH) treatment (Table 1, column 7). Growth of the remaining testis to a volume of $11 \mathrm{ml}$ was observed. Despite the persistence of TARTs (Fig. 2), the patient spontaneously impregnated his wife twice during the course of the third year of gonadotropin treatment. The first pregnancy ended in miscarriage after amniocentesis in the 16th week of gestation, and the second progressed uneventfully, resulting in the birth of a healthy girl.

\section{Discussion}

This report illustrates the possible consequences, if no treatment is provided, on the male reproductive tract in SV CAH, namely gonadotropin suppression, but paradoxically normal virilization due to the presence of high levels of adrenal androgens, testicular growth failure, hyperplasia of TARTs, and arrested spermatogenesis. This case also highlights a successful alternative treatment option (i.e. gonadotropin replacement) that can restore fertility, if classical CAH treatment fails.

\section{Genetics}

One of the most common CYP21A2 mutations (g.655A/C $>$ G (IVS2-13A/C $>$ G), often referred to as I2G) was found to be homozygous in our patient. It arises through gene conversion from the pseudogene and introduces a new splice acceptor leading to aberrant splicing $(7,8)$. Although homozygous I2G leads to SW CAH in the majority of cases (9), in our patient it caused only SV CAH.

\section{Clinical aspects of SV CAH}

In SV CAH, the defect of 21-hydroxylase enzymatic function does not cause symptomatic mineralocorticoid deficiency. Therefore, our patient was not affected by SW during infancy. The latent glucocorticoid insufficiency was compensated by pituitary ACTH hypersecretion; consequently, despite the lack of treatment, the patient did not suffer from any Addisonian crises. Nevertheless, he did experience precocious pseudopuberty with the attendant precocious growth spurt and a premature epiphyseal closure, which resulted in his short stature.

Normal testosterone levels despite very low gonadotropin levels were the endocrine situation found in our patient at the age of 30 years in the absence of any treatment, indicating that testosterone was of adrenal origin, caused by adrenal androgen overproduction in the presence of 21-hydroxylase deficiency.

\section{Testicular adrenal rest tumors}

Our case illustrates that TARTs may be misdiagnosed as a Leydig cell tumor, but may also uncover 21-hydroxylase deficiency. This is consistent with findings that in $18 \%$ of patients with no classical CAH, a correct diagnosis is not made until or after the development of a testicular mass (10). The presence of bilateral tumors, absence of metastases, and a decrease in tumor size following glucocorticoid therapy provide clinical clues pointing toward the correct diagnosis $(11,12)$.

Heterotopic masses of the adrenal cortex in patients with CAH may be present not only in the mediastinum 
testis, but also in the spermatic cord and within the epididymis $(13,14)$. These tumors are characterized as TARTs, developing due to chronic ACTH stimulation $(15,16)$. Already present in $3.5 \%$ of male neonates with CAH (17), TARTs may later present as painful, irregular, firm, or enlarged testes (18), the volume of which may be mistaken for normal pubertal testicular growth (1). Upon ultrasound imaging, they present as unilateral or bilateral (19) hypoechogenic multifocal areas adjacent to the mediastinum, $0.2-4 \mathrm{~cm}$ in diameter, with blurred margins, usually avascular, rarely hypervascular. Histologically, TARTs resemble Leydig cell tumors, but do not contain Reinke's crystals (15). The similarities between the conditions are such that they can lead to unnecessary surgical intervention, i.e. orchiectomy.

This case shows that spermatogenesis can recover, even after long-standing uncontrolled CAH and persisting TARTs. This is all the more surprising, considering the description of the histological stages in uncontrolled CAH with TARTs (20), where hypertrophy and hyperplasia of adrenal rest cells are reversible only in the early stages. If left uncontrolled, further growth would lead to the compression of the rete testis, peritubular fibrosis, and hyalinization, with focal lymphocytic infiltrates, indicating an irreversible stage of damage to the testicular parenchyma.

\section{Hormonal changes and fertility impairment in poorly controlled male $\mathrm{CAH}$}

Our case further illustrates that if untreated for an extended period, $\mathrm{CAH}$ can result in an impairment of the hypothalamic-pituitary-gonadal axis. The patient's testes were peripubertal in size; therefore, it can be assumed that the impairment was already present during adolescence, resulting in absent testicular growth and spermatogenesis. Nevertheless, there were no symptoms of androgen deficiency, as the excess of adrenal steroids counterbalanced $\mathrm{T}$ deficiency. There are conflicting reports regarding the consequences of $\mathrm{CAH}$ on male reproductive function, ranging from normal fertility despite nonadherence to medication (21) to poor fertility $(3,22,23,24)$. In parallel to gonadotropin suppression by excessive adrenal androgens $(21,25,26)$, there is evidence that endogenous estrogens (such as estrone) that originate from the peripheral aromatization by adrenal androgens (such as androstenedione) (27) may also act on the hypothalamus to inhibit GNRH secretion and on the pituitary to decrease the responsiveness to GNRH $(28,29)$.

\section{Hormonal treatment and outcome}

Our case illustrates that even after adrenal androgen overproduction in $\mathrm{CAH}$ is restored to near-normality by a 'standard' glucocorticoid therapy, gonadotropin suppression and TARTs can persist, causing symptoms of androgen deficiency and persisting azoospermia.

Similar findings of low serum testosterone levels in the presence of low LH levels after reduction of adrenal androgen production by hydrocortisone replacement have been reported in $\mathrm{CAH}$ patients who were appropriately treated previously, but after periods of insufficient glucocorticoid therapy were again placed on controlled stringent replacement regimens (22). However, if high gonadotropin levels are found, they can be indicative of a testicular failure $(22,30)$. Whereas some investigators found that TARTs regressed and spermatogenesis was reactivated when glucocorticoid therapy was instituted or intensified $(11,31)$, others report that patients remain azoospermic $(27,32)$. The use of dexamethasone $(0.25$ $0.5 \mathrm{mg}$ p.o. administered in a single late-evening dose) with or without additional hydrocortisone doses $(12,33)$ and/or the addition of fludrocortisone are other current treatment options. The first options were not chosen due to our patient's fear of weight gain and other symptoms of Cushing's syndrome. Fludrocortisone was not considered, as an elevation of the patient's blood pressure was a concern.

\section{Gonadotropin (hCG/FSH) replacement}

Our case illustrates that low testicular testosterone production due to sustained LH suppression can be successfully normalized by hCG therapy, despite the persistence of TARTs and even at a very late stage of disease after 30 years with no treatment. The LHCG receptor in Leydig cells is stimulated by hCG due to its structural homology to LH (34). However, by exerting a negative feedback on the pituitary, this treatment hampered the reappearance of endogenous gonadotropin secretion. Therefore, a combined s.c. hCG and FSH treatment was required to fully replace the deficient gonadotropins and to initiate spermatogenesis. This therapy needed to be performed for a period of 21 months to reach a stable sperm count in the ejaculate, the sperm quality remaining unchanged with a persisting low sperm count after 21 months of continued gonadotropin replacement. The low sperm concentration, found in our patient, seemed to be compensated by enhanced sperm quality, as it enabled a spontaneous conception twice, 
without any need for assisted reproductive techniques. Remarkably, this fertility was achieved from a single hypoplastic and atrophic testis and even though TARTs regressed only partially.

\section{Surgery}

Surgical removal of TARTs by testis-sparing surgery, to decompress the mediastinum testis and to abolish obstruction of the seminiferous tubules, has been shown to be unsuccessful in improving semen quality (35).

\section{Artificial reproductive technology}

In cases where patients remain azoospermic, a combination of testicular sperm extraction and ICSI can constitute a viable treatment option (36).

\section{Conclusions}

Untreated SV 21-hydroxylase deficiency has to be kept in mind as a cause of hypogonadotropic hypogonadism. In male patients with $\mathrm{CAH}$, attention needs to be paid to testicular function not only during childhood and adolescence but throughout life, in concert with a sustained ACTH-suppressive and thus 17-OHP-suppressive treatment. The inhibition of adrenal androgen overproduction may prevent the impairment of gonadotropin secretion and thus prevent testicular growth failure during puberty and azoospermia. Moreover, adequate $\mathrm{CAH}$ treatment may prevent the development of adrenal rest tumors. However, our case illustrates that if an adequate treatment is established only at a late stage of untreated or insufficiently treated disease, additional gonadotropin substitution may be an option to restore fertility and to enable spontaneous conception.

\section{Declaration of interest}

The authors declare that there is no conflict of interest that could be perceived as prejudicing the impartiality of the research reported.

\section{Funding}

This research did not receive any specific grant from any funding agency in the public, commercial or not-for-profit sector

\section{Author contribution statement}

J Rohayem was responsible for patient care and wrote the manuscript; F Tüttelmann carried out the genetic analysis and edited the manuscript;
C Mallidis edited the manuscript; E Nieschlag was responsible for patient care, was the head of the department till 2008 and edited the manuscript M Zitzmann was responsible for patient care and edited the manuscript; and S Kliesch has been the head of the department since 2008 and edited the manuscript.

\section{Acknowledgements}

The authors thank Claudia Krallmann (MD) for patient care. They also thank the technical staff (Raphaele Kürten, Daniela Hanke, Sabine Rehr, Jolanta Körber, and Sabine Borchert) for sperm and hormone analyses and Sabine Preisler-Adams for the molecular genetic workup and support in the interpretation of the results.

\section{References}

1 Willi U, Atares M, Prader A \& Zachmann M. Testicular adrenal-like tissue (TALT) in congenital adrenal hyperplasia: detection by ultrasonography. Pediatric Radiology 199121 284-287. (doi:10.1007/ BF02018626)

2 Srikanth MS, West BR, Ishitani M, Isaacs HJ, Applebaum H \& Costin G. Benign testicular tumors in children with congenital adrenal hyperplasia. Journal of Pediatric Surgery 199227 639-641. (doi:10.1016/ 0022-3468(92)90466-K)

3 Cabrera MS, Vogiatzi MG \& New MI. Long term outcome in adult males with classic congenital adrenal hyperplasia. Journal of Clinical Endocrinology and Metabolism 200186 3070-3078.

4 Mouritsen A, Jørgensen N, Main KM, Schwartz M \& Juul A. Testicular adrenal rest tumours in boys, adolescents and adult men with congenital adrenal hyperplasia may be associated with the CYP21A2 mutation. International Journal of Andrology 201033 521-527. (doi:10.1111/j.1365-2605.2009.00967.x)

5 Vermeulen A, Verdonck L \& Kaufman JM. A critical evaluation of simple methods for the estimation of free testosterone in serum. Journal of Clinical Endocrinology and Metabolism 199984 3666-3672.

6 Kliesch S \& Cooper TG. Semen analysis: spermiogram according to WHO criteria. Urology 2008471 1550-1554 (doi:10.1007/s00120-008-1796-0)

7 Rodrigues NR, Dunham I, Yu CY, Carroll MC, Porter RR \& Campbell RD Molecular characterization of the HLA-linked steroid 21-hydroxylase B gene from an individual with congenital adrenal hyperplasia. EMBO Journal 19876 1653-1661.

8 Higashi Y, Hiromasa T, Tanae A, Miki T, Nakura J, Kondo T, Ohura T, Ogawa E, Nakayama K \& Fujii-Kuriyama Y. Effects of individual mutations in the P-450(C21) pseudogene on the P-450(C21) activity and their distribution in the patient genomes of congenital steroid 21-hydroxylase deficiency. Journal of Biochemistry 19914 638-644.

9 New MI, Abraham M, Gonzalez B, Dumic M, Razzaghy-Azar M, Chitayat D, Sun L, Zaidi M, Wilson RC \& Yuen T. Genotype-phenotype correlation in 1,507 families with congenital adrenal hyperplasia owing to 21-hydroxylase deficiency. PNAS 2013110 2611-2616. (doi:10.1073/ pnas.1300057110)

10 Rutgers JL, Young RH \& Scully RE. The testicular tumor of the adrenogenital syndrome. A report of six cases and review of the literature on testicular masses in patients with adrenocortical disorders American Journal of Surgical Pathology 198812 503-513. (doi:10.1097/ 00000478-198807000-00001)

11 Cutfield RG, Bateman JM \& Odell WD. Infertility caused by bilateral testicular masses secondary to congenital adrenal hyperplasia (21-hydroxylase deficiency). Fertility and Sterility 198340 809-814.

12 Cunnah D, Perry L, Dacie JA, Grant DB, Lowe DG, Savage MO \& Besser GM. Bilateral testicular tumours in congenital adrenal hyperplasia: a continuing diagnostic and therapeutic dilemma. Clinical 
Endocrinology 198930 141-147. (doi:10.1111/j.1365-2265.1989. tb03735.x)

13 Wilkins L, Fleishmann W \& Howard JE. Macrogenitosomia precox associated with hyperplasia of the androgenic tissue of the adrenal and death from corticoadrenal insufficiency. Endocrinology 194026 385-395. (doi:10.1210/endo-26-3-385)

14 Dahl EV \& Bahn RC. Aberrant adrenal cortical tissue near the testis in human infants. American Journal of Pathology 196140 587-598.

15 Clark RV, Albertson BD, Munabi A, Cassorla F, Aguilera G, Warren DW, Sherins RJ \& Loriaux DL. Steroidogenic enzyme activities, morphology, and receptor studies of a testicular adrenal rest in a patient with congenital adrenal hyperplasia. Journal of Clinical Endocrinology and Metabolism 199070 1408-1413. (doi:10.1210/jcem-70-5-1408)

16 Claahsen-van der Grinten HL, Otten BJ, Sweep FC, Span PN, Ross HA, Meuleman EJ \& Hermus AR. Testicular tumors in patients with congenital adrenal hyperplasia due to 21-hydroxylase deficiency show functional features of adrenocortical tissue. Journal of Clinical Endocrinology and Metabolism 200792 3674-3680. (doi:10.1210/ jc.2007-0337)

17 Bouman A, Hulsbergen-van de Kaa C \& Claahsen-van der Grinten HL. Prevalence of testicular adrenal rest tissue in neonates. Hormone Research in Paediatrics 201175 90-93. (doi:10.1159/000316531)

18 Avila NA, Shawker TS, Jones JV, Cutler GB Jr \& Merke DP. Testicular adrenal rest tissue in congenital adrenal hyperplasia: serial sonographic and clinical findings. American Journal of Roentgenology 1999172 1235-1238. (doi:10.2214/ajr.172.5.10227495)

19 Stikkelbroeck NM, Suliman HM, Otten BJ, Hermus AR, Blickman JG \& Jager GJ. Testicular adrenal rest tumours in postpubertal males with congenital adrenal hyperplasia: sonographic and MR features. European Radiology 200313 1597-1603. (doi:10.1007/s00330-002-1786-3)

20 Claahsen-van der Grinten HL, Hermus AR \& Otten BJ. Testicular adrenal rest tumours in congenital adrenal hyperplasia. International Journal of Pediatric Endocrinology 20092009 624823. (doi:10.1186/ 1687-9856-2009-624823)

21 Urban MD, Lee PA \& Migeon CJ. Adult height and fertility in men with congenital virilizing adrenal hyperplasia. New England Journal of Medicine 1978299 1392-1396. (doi:10.1056/NEJM197812212992505)

22 Stikkelbroeck NM, Otten BJ, Pasic A, Jager GJ, Sweep CG, Noordam K \& Hermus AR. High prevalence of testicular adrenal rest tumors, impaired spermatogenesis, and Leydig cell failure in adolescent and adult males with congenital adrenal hyperplasia. Journal of Clinical Endocrinology and Metabolism 200186 5721-5728.

23 Claahsen-van der Grinten HL, Otten BJ, Hermus AR, Sweep FC \& Hulsbergen-van de Kaa CA. Testicular adrenal rest tumors in patients with congenital adrenal hyperplasia can cause severe testicular damage. Fertility and Sterility 200889 597-601. (doi:10.1016/j.fertnstert.2007. 03.051)

24 Reisch N, Flade L, Scherr M, Rottenkolber M, Pedrosa Gil F, Bidlingmaier M, Wolff H, Schwarz HP, Quinkler M, Beuschlein F et al. High prevalence of reduced fecundity in men with congenital adrenal hyperplasia. Journal of Clinical Endocrinology and Metabolism 200994 1665-1670. (doi:10.1210/jc.2008-1414)

25 Radfar N, Bartter F, Easley R, Kolins J, Javadpour N \& Sherins R. Evidence for endogenous LH suppression in a man with bilateral testicular tumors and congenital adrenal hyperplasia. Journal of Clinical Endocrinology and Metabolism 197745 1194-1204. (doi:10.1210/ jcem-45-6-1194)

26 Augarten A, Weissenberg R, Pariente C \& Sack J. Reversible male infertility in late onset congenital adrenal hyperplasia. Journal of Endocrinological Investigation 199114 237-240.

27 Bonaccorsi AC, Adler I \& Figueiredo JG. Male infertility due to congenital adrenal hyperplasia: testicular biopsy findings, hormonal evaluation, and therapeutic results in three patients. Fertility and Sterility 198747 664-670.

28 Winters SJ \& Troen P. Evidence for a role of endogenous estrogen in the hypothalamic control of gonadotropin secretion in men. Journal of Clinical Endocrinology and Metabolism 198561 842-845. (doi:10.1210/ jcem-61-5-842)

29 Pitteloud N, Dwyer AA, DeCruz S, Lee H, Boepple PA, Crowley WF Jr \& Hayes FJ. Inhibition of luteinizing hormone secretion by testosterone in men requires aromatization for its pituitary but not its hypothalamic effects: evidence from the tandem study of normal and gonadotropinreleasing hormone-deficient men. Journal of Clinical Endocrinology and Metabolism 200893 784-791. (doi:10.1210/jc.2007-2156)

30 Balestrieri A, Zirilli L, Madeo B, Pignatti E, Rossi G, Carani C \& Rochira V. 21-hydroxylase deficiency and Klinefelter syndrome in an adult man: striking a balance between androgen excess and insufficiency. Journal of Andrology 200829 605-609. (doi:10.2164/ jandrol.107.004648)

31 Aycan Z, Bas VN, Cetinkaya S, Yilmaz Agladioglu S \& Tiryaki T. Prevalence and long-term follow-up outcomes of testicular adrenal rest tumours in children and adolescent males with congenital adrenal hyperplasia. Clinical Endocrinology 201378 667-672. (doi:10.1111/ cen.12033)

32 Stikkelbroeck NM, Hermus AR, Suliman HM, Jager GJ \& Otten BJ. Asymptomatic testicular adrenal rest tumours in adolescent and adult males with congenital adrenal hyperplasia: basal and follow-up investigation after 2.6 years. Journal of Pediatric Endocrinology and Metabolism 200417 645-653. (doi:10.1515/JPEM.2004.17.4.645)

33 Mouritsen A, Juul A \& Jørgensen N. Improvement of semen quality in an infertile man with 21-hydroxylase deficiency, suppressed serum gonadotropins and testicular adrenal rest tumours. International Journal of Andrology 201033 518-520. (doi:10.1111/j.1365-2605. 2009.00958.x)

34 Padron RS, Wischusen J \& Hudson B. Prolonged liphasic response of plasma testosterone to single intramuscular injections of human chorionic gonadotropins. Journal of Clinical Endocrinology and Metabolism 198050 1100-1110. (doi:10.1210/jcem-50-6-1100)

35 Claahsen-van der Grinten HL, Otten BJ, Takahashi S, Meuleman EJ, Hulsbergen-van de Kaa C \& Hermus AR. Testicular adrenal rest tumors in adult males with congenital adrenal hyperplasia: evaluation of pituitary-gonadal function before and after successful testis-sparing surgery in eight patients. Journal of Clinical Endocrinology and Metabolism 200792 612-615.

36 Marchini GS, Cocuzza M, Pagani R, Torricelli FC, Hallak J \& Srougi M. Testicular adrenal rest tumor in infertile man with congenital adrenal hyperplasia: case report and literature review. Sao Paulo Medical Journal 2011129 346-351.
Received 22 April 2013

Revised version received 20 December 2013

Accepted 6 January 2014 